\title{
Estudiantes activistas de la Facultad de Filosofía y Letras y su experiencia social en la acción colectiva de septiembre de 2018
}

\author{
Yazmín Cuevas, Melisa-Yolanda Pasos-Osnaya y Erika Romo-Romo
}

\section{RESUMEN}

El propósito de este artículo es analizar la experiencia social de estudiantes activistas de la Facultad de Filosofía y Letras de la Universidad Nacional Autónoma de México durante la acción colectiva que se desplegó, en septiembre de 2018, ante un ataque violento hacia la comunidad de alumnos. La investigación usó la propuesta de Dubet de experiencia social, resultado de la articulación de tres lógicas de acción: integración, estrategia y subjetivación. Se empleó la metodología cualitativa, mediante la cual se diseñaron y llevaron a cabo ocho entrevistas y cuestionarios a estudiantes activistas. En los resultados destaca que la lógica de integración a la acción colectiva de estos estudiantes se dio ante la indignación de los ataques a su comunidad y por solidaridad con ésta; la lógica de estrategia consistió en la generación de diferentes repertorios de acción colectiva (paros, marchas); la lógica de subjetivación implicó la crítica y aprendizajes frente a su participación en esta acción.

Palabras clave: estudiantes, experiencia de los estudiantes, acción colectiva, UNAM, México. 0494. 


\title{
Estudiantes ativistas da Faculdade de Filosofia e Letras e sua experiência social na ação coletiva de setembro de 2018
}

\section{RESUMO}

O propósito deste artigo é analisar a experiência social de estudantes ativistas da Faculdade de Filosofía y Letras da Universidad Nacional Autónoma de México durante a ação coletiva que sucedeu, em setembro de 2018, ante um ataque violento contra a comunidade de alunos. A investigação usou a proposta de Dubet de experiência social, resultado da articulação de três lógicas de ação: integração, estratégia e subjetivação. Se empregou a metodologia qualitativa, mediante a qual se desenharam e desenvolveram oito entrevistas e questionários a estudantes ativistas. Nos resultados destaca que a lógica de integração à ação coletiva destes estudantes se deu pela indignação dos ataques a sua comunidade e pela solidariedade com esta; a lógica de estratégia consistiu na geração de diferentes repertórios de ação coletiva (greves, marchas); a lógica de subjetivação implicou na crítica e aprendizagens como consequência da sua participação nesta ação.

Palavras chave: estudantes, experiência dos estudantes, ação coletiva, UNAM, México.

Activist students of the Faculty of Philosophy and Letters and their social experience during the collective action of September 2018

\begin{abstract}
The purpose of this article is to analyze the social experience of activist students enrolled in the Faculty of Philosophy and Letters of the National Autonomous University of Mexico during the collective action that was carried out in September 2018 as an answer to a violent attack towards the student community. The research used Dubet's proposal of social experience, which results from the articulation of three logics of action: integration, strategy and subjectification. The author makes use of a qualitative methodology by means of eight interviews and questionnaires that were carried out with student activists. The results show that the logic of integration to the collective action of these students was due to the indignation of the attacks on their community and in solidarity with it; the logic of strategy consisted in the generation of different repertoires of collective action (strikes, marches); the logic of subjectivation implied criticism and learning from their participation in this action.
\end{abstract}

Keywords: students, student experience, collective action, UNAM, Mexico.

Recepción: 21/09/19. Aprobación: 11/12/20. 


\section{Introducción}

El 3 de septiembre de 2018, frente al edificio de rectoría de la Universidad Nacional Autónoma de México (UNAM), mientras estudiantes de bachillerato y licenciatura realizaban una protesta fueron agredidos por un grupo de porros - como se le llama en México a los grupos de alumnos provenientes de las escuelas de educación media superior y superior que cometen actos de violencia organizada- Esto desató la indignación de la comunidad estudiantil, que organizó una acción colectiva consistente en marchas y paros para reclamar a las autoridades un cese de la violencia en diferentes campus de esta institución. Particularmente, la Facultad de Filosofía y Letras (FFyL) tuvo tres semanas de paro de actividades y muchos de sus estudiantes se distinguieron por su alta participación y organización en la acción colectiva puesto que contaban con experiencias previas de protesta.

En este contexto se emprendió una investigación con el propósito de comprender - más que describir, clasificar o dar cuenta de la lucha entre los actores políticos de la organización estudiantil y las autoridades - mediante la propuesta de Dubet (1994), la experiencia social de estudiantes activistas de la FFyL. Las preguntas a las que responde este artículo son: ¿cómo se integraron estos estudiantes activistas a la acción colectiva?, ¿qué mecanismos de estrategia pusieron en juego en la participación de la organización de acción colectiva?, y ¿qué obstáculos y ventajas tuvo, desde su perspectiva, esta acción?

El artículo se compone de cinco apartados: en el primero se presenta el referente teórico en el que descansó la investigación; en el segundo se expone el contexto situacional, es decir los eventos del mes de septiembre de 2018 y las particularidades que tuvieron en la FFyL; en el tercero se describe el procedimiento metodológico; en el cuarto se muestran los resultados del análisis empírico; por último, en el quinto se exponen las consideraciones finales.

\section{Marco de referencia}

Para indagar la experiencia social de los estudiantes activistas se recurrió a tres elementos conceptuales: acción colectiva, experiencia social y estudiantes activistas.

\section{Acción colectiva}

En este estudio se optó por apegarse al concepto de acción colectiva dado que "su carácter es menos restrictivo en relación con los movimientos sociales en el sentido que permite registrar una serie de acciones y diversidad de actores que se organizan para plantear demandas a las entidades que consideran pertinentes, sin que necesariamente exista una organización formal o permanente" (Mora, 2008: 136). Mientras que, de manera general, un movimiento social, en este caso estudiantil, se distingue por la presencia de un conflicto, una colectividad que adquiere identidad y se convierte en un actor político, cuenta con adversarios, aliados, repertorios de acción colectiva, una mayor permanencia en el tiempo y presencia en el escenario de la política nacional e incluso internacional.

La acción colectiva es tratada mediante diferentes ángulos conceptuales, donde retomamos a Touraine (1987), quien señala que ésta nace de la voluntad de los actos conformados por grupos con el propósito de preservar la solidaridad ante conflictos con las autoridades y el orden establecido. Otra perspectiva es representada por Melucci (1991: 350) que considera que la acción colectiva es el "resultado de intenciones, recursos y límites, con una orientación constituida por medio de relaciones dentro de un sistema de oportunidades y acciones [donde] los individuos actúan conjuntamente [...] definen términos cognoscitivos, afectivos y relacionales en el campo de posibilidades y límites que perciben". El conflicto es entendido como la oposición entre dos o más actores por los mismos recursos a los que le atribuyen un valor. La acción colectiva se asocia a un conflicto que es el que da origen a la misma y del que emana la congregación de actores como una unidad para 
generar acciones como marchas, paros o huelgas, por mencionar algunas. Esto posteriormente puede dar lugar a negociaciones con los adversarios para conseguir los propósitos trazados o su mayor parte. Un aspecto que destacan Tarrow (1997), Melucci (1991) y Touraine (1987) es que la acción colectiva lleva a establecer solidaridad entre sus actores, quienes así se identifican como una unidad social.

Por su parte, Tarrow (1997) advierte que la acción colectiva se constituye por protestas como marchas, paros de actividades o bloqueos de avenidas. $\mathrm{Al}$ respecto, McAdam et al. (2001) agregan un atributo, que denominan repertorios de acción colectiva, el cual implica la suma de prácticas que despliegan, comparten y ejercen los actores para evidenciar el conflicto ante sus adversarios. Estos autores advierten que los actores que participan en la acción colectiva incorporan y adaptan rutinas propias de su contexto sociohistórico.

Existen diversas clasificaciones de repertorios de acción colectiva (Tarrow, 1997). Una tipología conveniente para América Latina y los conflictos estudiantiles es la que propone Tricot (2012: 12), quien señala tres tipos de repertorios: tradicionales, compuestos por marchas, tomas de edificios, paros de actividades, huelgas; renovados, que incorporan elementos como el humor y el arte a los tradicionales; nuevos repertorios, que involucran el empleo de los espacios públicos en cuanto escenarios donde tienen lugar las protestas con "formas novedosas, pacíficas, creativas e incluso irónicas".

Por otra parte, un ángulo que suele pasarse por alto en el estudio de la acción colectiva es lo que sucede con sus actores, ya que en el desarrollo de ésta se dan interpretaciones, tensiones, emociones, valoraciones y aprendizajes entre ellos. $\mathrm{Al}$ respecto, Dubet (2011: 36) señala que "detrás de las categorías de orden y reproducción, basta tomarse el trabajo de ver que la vida social se construye como un drama, como un conjunto de tensiones, de luchas y de resistencia". Este autor, en sus inicios, trabajó en el enfoque de nuevos movimientos sociales con Touraine y se interesó en develar la experiencia social de los actores, el concepto central de esta investigación.

\section{Experiencia social}

Para explicar la experiencia social es necesario recurrir a Berger y Luckman (2001) quienes señalan que la realidad social es una construcción compartida, interpretada y modificada por sus actores para que el mundo tenga un significado coherente. La realidad social se crea y recrea en las acciones que emprenden éstos, para quienes ésta se da por sentada. Con todo, ante los actores se presentan situaciones y problemas desconocidos que necesitan enfrentar, aquí tiene lugar la experiencia social. De acuerdo con Dubet (1994), el mundo social no está completamente adaptado a los actores, por lo que éstos, de manera permanente, interpretan las situaciones, los objetos, las personas, las normas. Los actores ante ciertos acontecimientos explican y justifican sus acciones; por lo que recurren a la experiencia social con la que cuentan, que es una actividad subjetiva por la que le confieren sentido a sus actos (Guzmán, 2012).

Con el objeto de clarificar la experiencia social apelamos a Durkheim (1991) para quien el actor se conforma de un ser individual y un ser social. El primero hace referencia a las características distintivas que configuran de manera singular a cada ser humano como los procesos mentales, la personalidad, el cuerpo. Mientras que el ser social se constituye por la incorporación de las normas, reglas, leyes y creencias indispensables por las que el actor se inserta en un grupo, institución o país. Así, la experiencia social se ubica entre las estructuras sociales y las acciones individuales, como una suerte de códigos que se encuentran disponibles en un acervo cultural para designar a las cosas, las situaciones y los sentimientos. Podría pensarse que las acciones de los actores son puramente individuales, pero toda acción es mediada, observada y reconocida por los otros actores sociales (Dubet, 1994). 
Cada experiencia social de los actores es el resultado de la articulación de tres lógicas de acción, a saber: la integración, la estrategia y la subjetivación (Dubet, 1994). La lógica de integración comprende la definición que hace el actor de su pertenencia grupal y social, para mantenerse o reforzar su permanencia en los mismos. La lógica de estrategia implica la revisión que hace el actor de sus recursos para enfrentar las situaciones desconocidas (Guzmán, 2012). La lógica de subjetivación conlleva un análisis crítico de parte del actor para confrontar una sociedad, definida como un sistema de producción y dominación. Estas tres lógicas son autónomas y no están jerarquizadas, es decir ninguna es más importante que la otra.

Para analizar la experiencia social Dubet (1994) propone tres operaciones fundamentales: la primera de ellas requiere efectuar un orden analítico, donde es preciso separar y describir cada experiencia concreta. La segunda consiste en comprender la actividad que despliega el actor ante las situaciones inusitadas y cómo la articula con las tres lógicas (integración, estrategia y subjetivación). Por último, para la tercera operación se debe identificar cómo sintetizan los actores estas lógicas y las catalizan tanto en el plano individual como colectivo.

\section{Estudiante activista}

Con respecto al estudiante activista, es difícil ofrecer una noción puntual, dado que involucra componentes que dependen del contexto social y político donde se encuentre inserto este actor. Lo que se pretende es ofrecer un cuerpo de rasgos que distinguen a un estudiante activista. En principio, es un actor social que cursa, generalmente, sus estudios en la educación superior con el propósito de obtener una formación profesional y cuyo estatus es temporal (Coulon, 2005). Dubet (2005) considera dos aspectos que conforman la categoría de estudiante: juventud y estudios. El primero refiere a la edad, que generalmente es entre 18 y 30 años - no obstante, pueden existir estudiantes mayores-, son actores que se encuentran en una transición hacia la adultez, que involucra responsabilidades económicas, sociales e incluso emocionales. Por ejemplo, distanciamiento de la familia, manutención económica, asumir posiciones políticas, búsqueda de trabajo, decisiones sobre su carrera profesional. El segundo elemento son los estudios; incluye los objetivos profesionales, intereses intelectuales, así como la manera en que se integran al sistema escolar que les exige un compromiso reglamentado (asistencia a clases, realización de exámenes o actividades profesionales). De acuerdo con Dubet (2005: 3) "el estudiante no se puede reducir ni a su papel ni a su condición, sino que elabora una experiencia que articula una manera de ser joven y una relación con los estudios". Para este autor el ser estudiante implica conformar una experiencia social que se configura de tres aspectos: 1) integración del actor con el marco de la institución de educación superior; 2) formación de proyectos en el sentido de utilidad social de los estudios y 3) vocación (emerge de la actividad crítica, es la influencia de la carrera sobre la personalidad, la manera de interpretar el mundo y desenvolverse en él).

Ahora bien, con respecto a la noción de estudiante activista autores como Garrido (2015), García (2011), Marsiske (2011), Palomino (2010), Aranda (2000) y Garreton (1987), coinciden en que son actores sociales interesados en la situación política, económica y social de su institución de educación superior, de su país y del mundo. Usualmente, militan en organizaciones políticas y generan acción colectiva con el propósito de conseguir un cambio social que beneficie tanto a su comunidad estudiantil como al resto de los ciudadanos (Lozano, 2017).

\section{Escenario de la investigación: la UNAM en septiembre de 2018}

Para comprender el origen y desarrollo de la acción colectiva de septiembre de 2018 en la UNAM es necesario entender dos etapas del mismo: la primera protagonizada por estudiantes del Colegio de Ciencias 
y Humanidades (CCH), plantel Azcapotzalco; la segunda que convocó a una comunidad más amplia de escuelas y facultades de esta casa de estudios y a la cual se adhirieron comunidades de otras instituciones de educación superior (IES) (ver anexo 1).

\section{Origen y conflicto}

El 27 de agosto de 2018 la comunidad de estudiantes del CCH Azcapotzalco, ${ }^{1}$ inconforme con las prácticas de la dirección del plantel, organizó un paro de labores académico-administrativas. Entre sus demandas destacaban cursos que no contaban con profesores, cierre de cajas para el pago de inscripciones - lo que obligaba a realizar depósitos bancarios de 100 pesos cuando la cuota es de 20 centavos - y la eliminación de murales estudiantiles en los edificios del plantel. Durante el paro los estudiantes sufrieron agresiones por porros (Cruz, 2018), que son grupos de alumnos que actúan en favor de las autoridades y otros actores políticos - ya sea institucionales, gubernamentales o de partidos políticos-, para lograr sus propósitos, utilizan métodos violentos como hostigamiento, robo y violencia física (Ordorika, 2008). ${ }^{2}$ Se debe advertir que la connotación de porro se originó en los años de 1950 con las porras de jóvenes en los partidos de fútbol americano, posteriormente éstas se conformaron sólo por hombres y se incorporaron a las discusiones de las comunidades estudiantiles para interrumpirlas, causar brotes violentos en preparatorias, generar confusión en acciones colectivas (marchas, paros, tomas de instalaciones) (Lomnitz, 1989).

Ante la violencia que experimentaron los estudiantes del CCH-Azcapotzalco, elaboraron un pliego petitorio donde destacaban las siguientes demandas:
- Asignación puntual de profesores en los cursos antes del inicio del semestre.

- Respeto de la dirección a las expresiones político-culturales de la comunidad estudiantil.

- Desarticulación de los grupos porriles.

- Garantías de que los estudiantes que participaron en el paro no tuvieran represalias por parte de la dirección del plantel.

Posteriormente, los estudiantes del CCH Azcapotzalco se sumaron al reclamo de la comunidad del plantel Oriente, que exigía claridad y justicia por el feminicidio de la alumna Miranda Mendoza. Con estas consignas se convocó, el 3 de septiembre, a la comunidad de la UNAM a participar en una marcha que salió del CCH Azcapotzalco y culminó en el edificio de Rectoría ubicado en Ciudad Universitaria. A la protesta asistieron estudiantes de diferentes planteles del CGH, de la Escuela Nacional Preparatoria (ENP) y de la FFyL. Fuera de Rectoría, en espera de una respuesta de parte de las autoridades, los estudiantes fueron fuertemente agredidos por lo menos por tres grupos de porros (denominados Treinta y dos, Tres de marzo y la Federación de Estudiantes de Naucalpan) (Camacho, 2018). Como consecuencia, 14 estudiantes resultaron heridos, tres de ellos de gravedad, de los cuales dos formaban parte de la comunidad de la FFyL.

\section{La acción colectiva entre el 3 de septiembre y el 10 de octubre de 2018}

Entre el 3 y 4 de septiembre, 40 planteles de la UNAM (CGH, ENP, escuelas y facultades) en sus respectivas asambleas estudiantiles decidieron emprender una serie de paros de actividades

\footnotetext{
${ }^{1}$ La UNAM tiene nueve planteles de Escuela Nacional Preparatoria y cinco de Colegio de Ciencias y Humanidades que ofrecen bachillerato, 15 facultades en la zona metropolitana y ocho escuelas nacionales en diferentes ciudades del país con programas de licenciatura y posgrado. El principal campus se encuentra en la Ciudad de México, al que se le conoce como Ciudad Universitaria.

${ }^{2}$ De acuerdo con Ordorika (2008: 473) "el término genérico porrismo denota a un conjunto diverso de hechos de violencia que tienen lugar en el espacio educativo y que están conectados [...] a las prácticas de control corporativo que ha caracterizado al régimen político de México".
} 
académico-administrativas y marchas para demostrar su inconformidad ante los hechos violentos relatados anteriormente, conformando con ello una acción colectiva.

La organización estudiantil acordó una marcha el 5 de septiembre dentro de Ciudad Universitaria (CU) que partiría de la Facultad de Ciencias Políticas y Sociales (FCPS) hacia la Rectoría. A esta protesta, de acuerdo con los organizadores, acudieron 60000 participantes, de la UNAM y de otras comunidades, tales como el Colegio de México, la Escuela Nacional de Antropología e Historia, el Instituto Politécnico Nacional, la Universidad Autónoma Metropolitana, la Universidad Pedagógica Nacional, solamente por mencionar algunas (Sánchez y Camacho, 2018a). Los propósitos de la marcha fueron reclamar a las autoridades universitarias la desaparición de los grupos porriles, el cese de agresiones contra estudiantes dentro de los planteles de la UNAM y la eliminación de la violencia de género en esta universidad y el país. Como se puede observar, el conflicto escaló en demandas, ya no sólo era la violencia porril. Al cierre de la marcha, la organización estudiantil acordó desarrollar asambleas en los diferentes planteles de la institución para decidir si continuaban o levantaban el paro de actividades. La figura que tomó una presencia transcendente para la organización de la acción colectiva fue la Asamblea Interuniversitaria, donde participaban tanto estudiantes de escuelas y facultades de la UNAM como de otras IES; así como la Asamblea Interuniversitaria de Mujeres $^{3}$ que trabajó ampliamente en torno a la violencia de género en las universidades y dentro de la misma organización estudiantil. Posteriormente, la comunidad estudiantil de la UNAM conformó la Asamblea InterUNAM, compuesta únicamente por escuelas y facultades de dicha institución para discutir las problemáticas específicas de la misma.
Por su parte, el 4 de septiembre, el rector de la UNAM, Enrique Graue, condenó los actos violentos (Graue, 2018a). En los días siguientes se suspendió a Jesús Teófilo Licona, coordinador operativo de vigilancia de la Universidad, se expulsó a 18 estudiantes, identificados como porros, que participaron en la agresión de Rectoría y se expresó la apertura al diálogo con las comunidades de los diferentes planteles para atender sus demandas.

El 7 de septiembre tuvo lugar en el campus de CU la Asamblea Interuniversitaria, la cual duró 15 horas, donde ante las agresiones del 3 de septiembre, 50 representantes de diferentes IES dieron a conocer sus pliegos petitorios. Entre los acuerdos destacó: a) la organización de una marcha de protesta el 13 de septiembre que seguiría la misma ruta de la "marcha del silencio" que tuvo lugar 50 años atrás con el movimiento estudiantil de 1968, b) esclarecimiento y castigo a los responsables de los actos del 3 de septiembre, c) democratización de las universidades, d) educación pública y gratuita, e) transparencia y rendición de cuentas en las IES, f) cese de la violencia de género, g) atención a las exigencias locales de las comunidades (Sánchez y Camacho, 2018b). Se observa que en la discusión se integraron otros problemas que trascendían a la UNAM y que requerían de diálogo con otros actores políticos (Secretaria de Educación Pública, Secretaría de Gobernación, Secretaría de Hacienda). Con tal dispersión y diversidad, quizá, comenzó a diluirse el motivo que congregaba a los estudiantes en el ejercicio de la acción colectiva, ya que se perfiló la imposibilidad de consensuar un pliego petitorio interuniversitario.

Para el 12 de septiembre el rector de la UNAM acudió al CCH Azcapotzalco para reunirse con los estudiantes y solucionar sus demandas (Graue, 2018b). Como consecuencia, entre el 10 y 11 de septiembre una buena parte de facultades, escuelas,

\footnotetext{
${ }^{3}$ Esta figura se conformó en marzo del 2018 en el marco del Día de la Mujer como un espacio de discusión con respecto a la violencia contra las mujeres dentro de la Universidad.
} 
preparatorias y CCH levantaron el paro de actividades, con lo cual se desmovilizó un número significativo de estudiantes, porque quizá consideraban que las demandas habían sido cumplidas. La "marcha del silencio" del 13 de septiembre de 2018 tuvo como invitados distinguidos al Comité de 1968, familiares de los 43 estudiantes de la Escuela Normal de Ayotzinapa desaparecidos en 2014 y a los estudiantes del CCH Azcapotzalco (Sánchez y Camacho, 2018c), con lo cual se incorporaron otros grupos que, probablemente, sumaban otros propósitos a la acción colectiva emprendida.

El viernes 14 de septiembre una vez más tuvo lugar la Asamblea Interuniversitaria, donde tras deliberar 20 horas, los estudiantes no lograron concretar su pliego petitorio para las autoridades, debido a la dispersión de problemas que se intentaban tratar. Solamente coincidieron en tres puntos: inseguridad, asuntos de violencia de género y democratización de las universidades (Sánchez y Camacho, 2018d). El 17 de septiembre solamente la FFyL y la Escuela Nacional de Trabajo Social continuaban en paro de actividades. Al reanudarse las clases en la mayoría de las escuelas y facultades comenzó el declive de la acción colectiva.

En la Asamblea Interuniversitaria del 29 de septiembre, por tercera ocasión, no se consiguió formular los objetivos generales de la movilización estudiantil. Sin embargo, el 10 de octubre la Asamblea Estudiantil InterUNAM presentó el pliego petitorio con un alto número de demandas de toda índole, donde destacaron la erradicación de la violencia hacia estudiantes dentro de los campus, la eliminación de la violencia de género, el incremento y transparencia de recursos financieros en la UNAM, la educación pública y gratuita, la democratización de la universidad y la reparación de los daños a las víctimas de la agresión porril. A través de un comunicado, el rector señaló que las demandas eran amplias y complejas, así que se intentaría encausar su discusión por los canales institucionales (Sánchez, 2018).
En seguida la acción colectiva cesó en gran parte de la UNAM, no obstante, el 12 de octubre, los activistas que se mantenían organizados hicieron entrega en el Congreso de la Unión, del pliego petitorio de la Asamblea Interuniversitaria que finalmente logró concluirse integrando exigencias similares a las del pliego petitorio elaborado por la Asamblea Inter UNAM. Las autoridades correspondientes no proporcionaron respuesta alguna.

\section{La comunidad de estudiantes de la FFyL}

Uno de los elementos por los que se destacó la protesta ante la violencia en los campus de la UNAM, fue que en cada escuela y facultad se siguió un curso diferente. Como ya se señaló, la FFyL fue uno de los últimos establecimientos en levantar el paro de labores. Sus activistas tuvieron un papel importante en la coyuntura de septiembre, además entablaron lazos con estudiantes de otras facultades para apoyar la organización de la acción colectiva. Por ejemplo, para sugerir algunos criterios básicos en el ejercicio de un paro académico-administrativo, lineamientos para la conducción de asambleas estudiantiles, establecimiento de seguridad en las marchas.

En esta Facultad, el paro de actividades duró tres semanas. Durante las dos primeras se desplegaron diferentes repertorios de acción colectiva como foros de trabajo y discusión sobre las peticiones estudiantiles, marchas, performance, entre otras. La tercera semana se denominó autogestiva y estuvo a cargo de grupos que emprendieron algunas actividades de reflexión y discusión en torno a los problemas del momento. El 24 de septiembre se reiniciaron las clases en la FFyL.

\section{Encuadre metodológico}

Para indagar la experiencia social de los estudiantes activistas de la FFyL en la acción colectiva de septiembre de 2018 se optó por una metodología cualitativa que atiende a las formas en que el mundo social es interpretado y experimentado por los 
actores (Vasilachis, 2006), por lo que se necesitó de la generación de instrumentos de recolección de información empírica flexibles y pertinentes al contexto social en el que se encuentran los actores.

En este sentido, para acercarse a la experiencia de los estudiantes activistas se definieron cuatro ejes de análisis que derivaron de la discusión conceptual: $a c^{-}$ ción colectiva de septiembre de 2018, lógica de integración, lógica de estrategia y lógica de subjetivación. Una vez que se establecieron y definieron éstos, se generaron preguntas por cada uno, las cuales se retomaron para el diseño de una guía de entrevista semiestructurada. Además, se elaboró un cuestionario cerrado con el propósito de recuperar información que permitiera delinear las características sociales de los estudiantes activistas.

Un aspecto relevante de la investigación fue la selección de los participantes del estudio, ya que interesaba conocer la experiencia social de quienes intervinieron de forma destacada en la organización estudiantil de septiembre de 2018. Así se definieron los criterios para la elección de estudiantes: estar inscritos en la FFyL, haber participado de manera activa en las asambleas de estudiantes en la FFyL y formar parte de la organización de acción colectiva. Bajo tales criterios, se contactó a ocho estudiantes activistas, a quienes se les realizó la entrevista y aplicó el cuestionario.

El análisis de las entrevistas se apegó a la propuesta de Gibbs (2014), que consistió en identificar temas recurrentes vinculados a actos, estrategias y significados relacionados con la acción colectiva de septiembre de 2018. Estos temas dieron lugar a categorías de análisis que se sometieron a la revisión exhaustiva donde algunas prevalecieron y otras se descartaron bajo el principio de vinculación con las lógicas de integración, estrategia y subjetivación de experiencia social que propone Dubet (1994).

Con los datos del cuestionario se ubicaron características de los participantes del estudio. Cuatro activistas eran mujeres y cuatro hombres (ver cuadro 1). Con respecto a la edad, tenían entre 21 y 27 años. Eran solteros, estudiantes regulares de quinto y séptimo semestre, con promedios de entre 8.1 y 9.7. Una parte importante de los participantes en el estudio había cursado su bachillerato en la UNAM, por lo que conocía la organización y estructura universitaria.

\section{Cuadro 1. Condiciones de los estudiantes activistas}

\begin{tabular}{|c|c|c|c|c|c|}
\hline Clave & Sexo & Edad & Bachillerato de egreso & Carrera & Semestre \\
\hline E01 & $\mathrm{H}$ & 22 & ENP 8 & Pedagogía & 7 \\
\hline E02 & M & 21 & ENP 6 & Desarrollo y Gestión Interculturales & 5 \\
\hline E03 & M & 23 & ENP 9 & Filosofía & 7 \\
\hline E04 & $\mathrm{H}$ & 27 & Vocacional 3 & Historia (SUA) & 5 \\
\hline E05 & $\mathrm{H}$ & 23 & Privado & Letras Inglesas & 7 \\
\hline E06 & $\mathrm{H}$ & 24 & $\mathrm{CCH}$ Sur & Estudios Latinoamericanos & 7 \\
\hline E07 & M & 22 & $\mathrm{CCH}$ Vallejo & Estudios Latinoamericanos & 5 \\
\hline E08 & M & 21 & ENP 9 & Filosofía & 5 \\
\hline
\end{tabular}

Fuente: elaboración propia a partir del análisis del material empírico. 
Sobre la escolaridad de las madres de los entrevistados, cuatro tenían licenciatura, tres bachillerato y una posgrado. En cuanto a los padres, dos contaban con posgrado, 2 con licenciatura, uno con bachillerato, uno con carrera técnica, uno con secundaria y uno con primaria. Seis estudiantes reportaron que ya sea su madre, padre o ambos habían participado en movimientos estudiantiles de la UNAM. Desde el movimiento estudiantil de 1968 hasta el de 1999. ${ }^{4}$ Y un estudiante señaló que su padre formaba parte de un movimiento ciudadano. Así, los entrevistados, a través de sus familiares, ya habían tenido contacto y experiencias en movimientos estudiantiles, lo que puede ser una explicación de su presencia y activismo en septiembre de 2018.

\section{Resultados}

El análisis de las entrevistas develó que la experiencia social en la acción colectiva de los estudiantes activistas se conformó en respuesta a la indignación de los ataques violentos a su comunidad, por solidaridad con la misma y la historia de su grupo familiar en movimientos estudiantiles. En este sentido, generaron diferentes repertorios de acción colectiva (paros, marchas), así como una crítica con respecto al ejercicio de éstas y los aprendizajes que les dejaron. A continuación, se presentan los resultados de acuerdo con las lógicas de integración, estrategia y subjetivación (Dubet, 1994).

\section{Lógica de integración: conformación de la acción colectiva}

Para Dubet (1994) la lógica de integración se compone por la definición que hace el actor en relación con su adscripción, pertenencia y atribución social a un grupo. De acuerdo con los testimonios de los estudiantes activistas, el principio integrador de la acción colectiva fue la exigencia del cese a la violencia en los campus y manifestarse resueltamente en contra de grupos que propagan las agresiones en la UNAM: los porros. Además, en el análisis de las entrevistas apareció de manera recurrente que el ataque de los porros en la explanada de rectoría el 3 de septiembre fue un hecho que generó indignación y que recordó a los estudiantes activistas su pertenencia como estudiantes de la UNAM:

El movimiento despertó mucho sentimiento de que somos universitarios y por qué nos está pasando esto como universitarios (Estudiante_03).

Creo que en un primer momento nos representó a todos [...] también a muchos de los que se sentían muy universitarios y les dolió que hubiera porros feos (Estudiante_02).

La movilización buscaba representar las exigencias de los estudiantes (Estudiante_08).

Los activistas reconocieron un sentido de orgullo por formar parte de la comunidad universitaria, como una suerte de grupo social selecto al que se le denomina universitarios. Este término hace referencia a la adscripción de los que cursan estudios superiores y, por otro, a los miembros de una institución específica: la UNAM. Para los actores la pertenencia a una institución educativa, religiosa o política es parte de la socialización. En los testimonios se reconoce que los entrevistados consideran que forman parte de la comunidad de estudiantes de esta institución educativa. Además, en las entrevistas se perfila lo que Melucci (1991) denomina un "nosotros" que conlleva a que los actores se conformen como una unidad social donde se reconocen como estudiantes de la UNAM.

Un elemento de la lógica de integración es la oposición ellos/nosotros, dado que la diferencia, lo extraño y ajeno de los otros resalta los rasgos y cualidades del

\footnotetext{
${ }^{4}$ A lo largo de la historia de la UNAM han existido diferentes movimientos estudiantiles, el más conocido fue el de 1968 en parte porque fue de las primeras protestas generalizas en la Ciudad de México y porque culminó con la muerte de miles de estudiantes. En 1999 la UNAM tuvo una huelga estudiantil que duró nueve meses y que concluyó con la entrada de las autoridades federales al campus.
} 
grupo. Dubet (1994) afirma que no hay actor (yo), sin nosotros y sin ellos, esto es lo que lleva a la integración del grupo. Para conocer esto, se preguntó a los estudiantes a quiénes confrontaba la acción colectiva y quiénes eran sus adversarios:

Los adversarios fueron la Rectoría, fueron los directores, fueron las autoridades (Estudiante_01).

¿Los adversarios? Yo creo que es el Estado y es la estructura de la violencia [...] el Estado monopoliza la violencia y la ejerce contra todo aquel que no esté de acuerdo con él $[\ldots]$ los porros son el instrumento [...] la UNAM es el Estado (Estudiante_07).

El actor antagónico al que hizo frente la acción colectiva era el Estado como empleador de la violencia para presionar a los ciudadanos que no concuerdan con él. Para los estudiantes entrevistados, la UNAM como institución (no como comunidad) forma parte de la estructura opresora y violenta del Estado. Es decir, un elemento en la lógica de integración de estos estudiantes activistas es que los directores de escuelas y facultades, así como el rector, son vistos como autoridades que tienen la intención de imponer ciertas decisiones a través de métodos coercitivos. En los testimonios, los porros son vistos como una herramienta del Estado y la UNAM para ejercer la violencia. Esto no es algo nuevo: muchos conflictos estudiantiles hacen frente a las autoridades; sin embargo, tal parece que parte de la lógica de integración de estos estudiantes activistas es que las autoridades universitarias son un adversario con el que es difícil establecer un diálogo y negociar. Se observa que los activistas percibían a las autoridades representadas por directores de escuelas y facultades como los principales responsables del ambiente de inseguridad y desconfianza que impera en los distintos establecimientos de la casa de estudios.
En la lógica de integración aparecen los valores que comparten los actores con el grupo y que posibilitan su cohesión (Dubet, 1994). Al respecto, se indagó cuáles eran los valores que convocaron a la acción colectiva de septiembre de 2018:

Hubo un orgullo puma5 [...] en algún momento hubo solidaridad, como una cosa de acompañar, o sea a los estudiantes que fueron violentados (Estudiante_02).

Las personas que estábamos ahí en los paros y en las asambleas y en todo lo que sucedía era por una convicción propia [...] entonces como valores teníamos justicia, honestidad, fuerza, solidaridad, empatía, mucho amor (Estudiante_08).

En los testimonios anteriores aparece nuevamente el orgullo, que no es un valor sino un sentimiento de pertenencia a una comunidad de la UNAM. Estos estudiantes ostentan el compromiso con la acción colectiva que los lleva a actuar con determinación ante la causa que es detener la violencia en la institución e incluso la del país. Además, en las entrevistas aparece la solidaridad que en palabras de Melucci (1991: 390) es "la capacidad de los actores de reconocerse a sí mismos y ser reconocidos como la unidad social". Con lo cual se ubica que los estudiantes activistas en la lógica de integración trascendieron de una postura individual a la conformación de un nosotros como colectivo en las manifestaciones de septiembre de 2018.

\section{Lógica de estrategia: organización y amenazas en la acción colectiva}

Para Dubet (1994), en la lógica de estrategia, el actor hace una revisión de sus recursos para enfrentarse a situaciones desconocidas. Se entiende como recurso a las acciones planeadas para conseguir propósitos en común, para ello los miembros del grupo

\footnotetext{
${ }^{5} \mathrm{El}$ puma es la mascota del equipo de fútbol de la UNAM, y es costumbre que los miembros de la comunidad UNAM se identifiquen como "pumas".
} 
establecen normas y reglas que los regulan. La acción colectiva tiene lugar gracias a la capacidad de los actores para reconocerse en relación con los otros y contemplar sus posibilidades de actuar, por lo que éstos negocian y discuten para proyectar sus propósitos, alcances y límites de la acción colectiva que emprenden (Melucci, 1991). En este sentido, el órgano mayor que representó a la acción colectiva de 2018 fue la asamblea:

La infalible siempre ha sido la asamblea, creo que es una herramienta importante, que está muy mal vista (Estudiante_01).

Se da por niveles, primero eran las asambleas por escuela (bachilleratos, universidades, facultades) y después ya sea que fuéramos a la [asamblea general] de la UNAM, se organizaba una interUNAM (Estudiante_08).

Como bien lo señalan los testimonios, en algunos grupos de la UNAM impera el principio de someter a discusión y crítica las ideas y acciones que son de interés de la comunidad. Los activistas recurrieron a la asamblea como una forma para organizar la acción colectiva, debatir el pliego petitorio (es decir el propósito de la acción colectiva) y los repertorios de acción colectiva (por ejemplo, marchas y paros de actividades académico-administrativas). Estas asambleas son abiertas para toda la comunidad estudiantil, aunque la palabra es mayormente concentrada por los líderes estudiantiles, funcionan mediante la preparación de una orden del día y una discusión posterior (lo más organizada posible) para concretar puntos, acciones y tomas de posición política. Así, la asamblea es un recurso que forma parte de la lógica de estrategia (Dubet, 1994) de los estudiantes activistas, como una suerte de herramienta que conocen y dominan en términos de su duración, su conducción, los mecanismos de participación y seguramente los juegos políticos que se ponen en marcha para apoyar o desestimar determinadas proposiciones.
De las asambleas derivan las comisiones asignadas a grupos de estudiantes para hacerse cargo de las diferentes tareas y responsabilidades de la acción colectiva. Pueden ser actividades manuales (limpiar, cocinar) o actividades de orden intelectual (elaborar comunicados de prensa).

Como parte de la lógica de estrategia se ubicó que los estudiantes activistas proyectaron y recurrieron a los repertorios de acción colectiva (Mc Adam et al., 2001) que son esas rutinas aprendidas, compartidas y desplegadas para evidenciar los conflictos y presentar demandas de solución (Mora, 2008). En el análisis de las entrevistas los estudiantes relataron cuatro repertorios de acción colectiva: paros de actividades, marchas, foros de discusión y actividades artísticas. Los dos primeros pueden clasificarse como repertorios clásicos y los dos últimos como repertorios renovados (Tricot, 2012).

Como parte de los repertorios clásicos, los activistas señalaron que las primeras acciones que emprendieron fue acordar con representantes de la comunidad estudiantil el paro de actividades dentro de la FFyL. Este repertorio también fue emprendido por todas las escuelas y facultades de la UNAM. En cuanto a las propuestas de realización de marchas, donde participan más estudiantes que en las asambleas, se discutieron en la Asamblea InterUNAM y se llevaron a cabo.

Parte de las responsabilidades de acción colectiva que lideraban estos estudiantes eran establecer otras manifestaciones para dar a conocer el conflicto y las demandas de la comunidad, en este sentido dos estudiantes señalan:

Un compañero decía la maldita triada, porque era asamblea-marcha-paro, entonces fue como algo cíclico (Estudiante_06).

Hubo movilizaciones, asambleas, foros, se intentó hacer performance [...] se hicieron ofrendas, interpretaciones artísticas, representaciones teatrales (Estudiante_03). 
Los estudiantes activistas incorporaron repertorios renovados de acción colectiva para dar a conocer sus demandas, tales como foros de discusión, actividades culturales y artísticas; esto se entiende como un elemento distintivo de esta organización, que trató de llevar a cabo actividades que iban más allá de las marchas, vía clásica de las manifestaciones estudiantiles, con la intención de invitar a que participaran más estudiantes, profesores y trabajadores.

En las acciones colectivas contemporáneas no se desean líderes que acumulen todo el poder y presencia, sino representantes que se turnen los espacios de discusión y diálogo, sin embargo, en el análisis se encontró la alusión recurrente a estudiantes líderes. Para los estudiantes un factor indispensable en la organización y jerarquía de acción colectiva son los líderes, en el entendido de que representan a la unidad social y conducen muchos de los repertorios de acción colectiva. Los activistas reconocen que no es sencillo posicionarse como líder en la jerarquía de la organización, sino que hay un proceso:

Se dice que no es jerárquico, aunque, creo, muchas veces lo es. Es decir, siempre hay un compañero que grita más fuerte, que se pone al frente (Estudiante_04).

Se consolidan jerarquías "éste tiene tantos años haciendo paros, éste tiene poco". Ya dominan el lenguaje, ya dominan los métodos, ya dominan tal. Entonces llega el nuevo a poner una opinión diferente y simplemente es rechazado (Estudiante_01).

La experiencia previa de los estudiantes activistas es vital para posicionarse como líderes de la organización, debido a que dominan reglas y códigos que son esenciales para formar parte de una protesta, un paro de actividades y de una organización política. Parte de las reglas implícitas, dentro de la jerarquía, es que para convertirse en líder es un requisito tener antigüedad en la organización de paros y marchas, así como mostrar competencias en la tutela de acción colectiva. Los estudiantes activistas que recientemente se incorporan a la organización y a la vida política universitaria tendrán que esperar su turno, hacer antigüedad y adquirir mayor experiencia para convertirse en líderes. Esto puede ser contradictorio, ya que por un lado los estudiantes activistas apelan a la horizontalidad y pluralidad en las acciones colectivas, por otro en la organización y jerarquía de las luchas estudiantiles tal parece que hay reglas no dichas.

Ahora bien, en la acción colectiva de septiembre de 2018 la comunidad de estudiantes de la FFyL se posicionó frente a otras escuelas y facultades de la institución por su experiencia en diversas manifestaciones. Los activistas proyectaron una identidad de conocimiento acumulado en el colectivo estudiantil, se convirtieron en asesores de otras escuelas y facultades, y destacaron por el dominio en el ejercicio de la protesta.

La FFyL era consultada por todas las facultades, por todas las preparatorias, para preguntar ¿cómo se hace un paro?, ¿qué debo hacer? [...] Filosofía y Letras fue, digamos, como una nave nodriza, a la que muchas facultades recurrían si tenían problemas (Estudiante_01).

Según Dubet (1994) en la lógica de estrategia las relaciones son definidas en términos de convergencia, rivalidad, intereses colectivos e individuales, a lo que denomina concurrencia. En el entendido de que una sociedad es un sistema de intercambios negociados para obtener determinados propósitos (poder, dinero, prestigio, influencias, reconocimiento). En la acción colectiva de septiembre de 2018 el punto de cohesión fue la indignación y el cese de la violencia contra los estudiantes. Posteriormente, se fueron sumando otras demandas:

La organización [estudiantil] continúa en tanto hay grupos de estudiantes que se organizan para 
analizar ciertas teorías [...] aprovechan este pico de actividad [septiembre de 2018] para posicionar sus demandas (Estudiante_05).

Desde el principio tomó vertientes como de algunos sectores que estaban mucho más politizados y que traían lucha desde antes [...] llegaron conceptos que nos pusieron [...] tripartita, autónoma, sin realmente cuestionar si eso es lo que queríamos (Estudiantes_02).

En la FFyL hay grupos de estudiantes con organización y trayectoria política bastante amplias, además tienen una presencia permanente en la institución educativa para dar a conocer problemas y sumarse a acciones colectivas de otros grupos (maestros de educación básica, estudiantes de escuelas normales, trabajadores estatales, por señalar algunos). En las entrevistas se encontró que estos grupos incorporaron a la agenda de la organización estudiantil otras demandas como democratización de la UNAM, educación pública y gratuita. Así, la concurrencia de la lógica de estrategia trascendió a la integración o, como lo nombran los entrevistados, la imposición de otras exigencias a las autoridades de la casa de estudios y al gobierno mexicano. Es evidente que entre los estudiantes activistas hubo discusiones, disputas y tensiones para adjuntar más puntos al pliego petitorio, razón por la cual éste se concluyó casi mes y medio después de iniciado el conflicto, lo que desde el punto de vista de los entrevistados restó fuerza y presencia a la protesta. Esta concurrencia, de acuerdo con la experiencia de los entrevistados, llevó a que la acción colectiva tuviera dos ciclos: uno que agrupó peticiones contra el cese a la violencia en los campus de la UNAM y contra su comunidad; otro que representó a grupos con mayor trayectoria política en la institución cuyos reclamos se dirigieron a la exigencia de la democratización de la UNAM y que en el país existiera una educación pública y gratuita.

En la lógica de estrategia reiteradamente aparece la amenaza como la figura de la anomía o el egoísmo
(Dubet, 1994). Para indagar este aspecto se preguntó a los participantes del estudio cuáles eran las amenazas a la organización estudiantil:

\begin{abstract}
Más allá de las obvias, de Rectoría infiltrándose [...] de Graue sacando comunicado tras comunicado con mucho colmillo para intentar ganar el debate político. Más allá de eso creo que el movimiento tiene peligros en su interior, es decir el sectarismo, el andarnos viendo el ombligo, como creyendo que nosotros podemos contra todo sin hacer un análisis serio (Estudiante_04).
\end{abstract}

Uno de los aspectos que los activistas reconocieron como peligros fueron las actividades que estableció la autoridad universitaria para detener la acción colectiva, tales como la reunión del rector con la comunidad del CGH Atzcapozalco y la expulsión de los porros. Asimismo, los entrevistados se sintieron amenazados y amedrentados por personas que al parecer los espiaban, como una suerte de peligro latente de represión, que en México existe a través de la desaparición forzada, el encarcelamiento o las agresiones físicas. Otro riesgo que señalaron los activistas es de orden endógeno, el exceso de análisis de la UNAM, sus estructuras y comunidad por la misma colectividad, sin el reconocimiento de otras facetas y aspectos sociales de los ciudadanos y el país. También, un elemento de amenaza, desde la experiencia de los entrevistados, fue el sectarismo:

Son grupos que funcionan por cuadros políticos [...] tienen mucha capacidad de retórica y la usan en las asambleas para desarticular el movimiento y te hacen sentir como poco representado o incluyen intereses propios (Estudiante_07).

En las entrevistas los activistas externaron que en la FFyL existen diferentes grupos de estudiantes con posiciones e intereses políticos encontrados que, al parecer, son intolerantes ante las posiciones de otros 
grupos. Para los activistas, las amenazas a la organización de la acción colectiva fueron estos grupos por generar discrepancias e imponer demandas ajenas a los propósitos establecidos. Como consecuencia, una parte de los entrevistados señaló que cuando estos grupos tomaron la organización de la acción colectiva sintieron que ya no tenían representación. En este sentido Melucci (1991) afirma que dentro de la organización de acción colectiva hay tensiones para determinar sus fines y medios, así como los ambientes donde se ejecutarán. Aspectos latentes pero invisibilizados.

\section{Lógica de subjetivación: crítica a la acción colectiva}

Para Dubet (1994) las lógicas de subjetivación y estrategia permiten a los individuos desenvolverse en el grupo y las califica como positivas. Por su parte, la lógica de subjetivación es clasificada como crítica ya que, en determinado momento, el actor se cuestiona en torno a su rol social y sus compromisos con el grupo. Lo que aporta un ángulo distinto a la experiencia que vive. Así, en la lógica de subjetivación el compromiso que tiene el actor, en este caso con la acción colectiva de septiembre, se vive como inacabado, como una suerte de pasión imposible y el deseo permanente de percibirse como el constructor de su propia vida, lo que se distingue por la imposibilidad de realizarse plenamente (Dubet, 1994). Por eso, la acción colectiva de septiembre confrontó a los estudiantes entrevistados con los propósitos que se plantearon, los compromisos que adquirieron y los aprendizajes que les dejó. En cuanto a los propósitos, por un lado, los activistas tienen la claridad de que la manifestación de la comunidad estudiantil fue para cesar la violencia que se da en la UNAM; por otro, algunos entrevistados consideran, de manera crítica, que los paros de actividades y marchas que realizaron fueron expresiones de descontento y las autoridades universitarias dieron respuestas ambiguas a sus demandas. En los testimonios se observa que los estudiantes activistas examinan de manera aguda la organización de acción colectiva, así su experiencia se adhiere el reconocimiento de debilidades o puntos negativos:

Esto que vimos para nada fue un movimiento, fueron movilizaciones ante el ataque porril (Estudiante_06).

Es una encarnación del hartazgo ante una situación de violencia y una desatención de la violencia que nos pega diario (Estudiante_07).

En el discurso de los participantes del estudio resaltó el alto compromiso que establecieron con la acción colectiva: "Le di mi vida, dos meses de vida [...] no hice otra cosa que no fuera dedicarme a esto" (Estudiante_03).

Además, indicaron tener la responsabilidad de cuidar y vigilar la seguridad de los estudiantes que participaban en las marchas, que se quedaban a dormir en la FFyL, así como del resguardo de las instalaciones. Con respecto al compromiso un estudiante apunta:

Siempre he sentido el llamado a la movilización en general y, sobre todo, a la organización estudiantil. Entonces tengo un compromiso [...] cualquier cosa que vaya a suceder voy a estar ahí $[. .$.$] de al-$ guna forma puedo aportar algo y quiero hacerlo (Estudiante_08).

Con el anterior testimonio se observa que los entrevistados vivieron la acción colectiva como un llamado interior, una vez que se involucraron con el activismo de septiembre de 2018 trascendió su deber como universitarios a participar en la vida política de la institución aunado a las experiencias que tenían sus familias en participación de movimientos estudiantiles. En otras palabras, los estudiantes consideraron que el compromiso va más allá de un momento fugaz de marchas y paros, necesitan estar permanentemente en las esferas de la vida política 
universitaria y del país. Así, la participación de muchos de los estudiantes entrevistados fue su entrada al activismo, para otros el refrendo de su implicación en la toma de decisiones de la UNAM.

Los activistas apuntaron que la acción colectiva de septiembre fue una fuente de aprendizajes sobre la estructura organizativa de la UNAM, sus leyes, reglamentos y normas, el trabajo colectivo, la asignación de tareas y el cumplimiento de responsabilidades. También fue una lección dura con respecto al alcance que tuvo, a las faltas de organización, a la ausencia de objetivos políticos. Así, esta acción colectiva dejó aprendizajes a partir de que los estudiantes realizaran una valoración crítica del camino que siguió la organización, donde los testimonios son contundentes: la protesta no prosperó por falta de claridad. Además, el activismo y la lucha política sólo dan resultados a largo plazo, por lo que se necesita tiempo y persistencia. $\mathrm{Al}$ respecto, tres estudiantes afirman:

Aprendí a ser más paciente, uno se da cuenta de que no porque pares una semana la universidad, el mundo va a cambiar (Estudiante_03).

Aprendí sobre todo la solidaridad, sobre todo experiencia organizativa, porque ahora sé cuáles pueden ser los déficits o puntos fuertes de la organización (Estudiante_08).

Para mí deja una lección fundamental de que, si no hay claridad política, si no hay constancia en la organización, en futuras coyunturas va a pasar lo mismo, así de simple, no van a trascender en realidad este tipo de movilizaciones (Estudiante_06).

En los testimonios se advierten las dificultades que tuvieron los estudiantes en su experiencia con la acción colectiva. En este sentido, Dubet (1994) afirma que, desde el punto de vista social, las relaciones de los actores con respecto a los fines y propósitos que tienen en el grupo son percibidos como obstáculos. Así, en la lógica de subjetivación los activistas dan cuenta de que en sus propósitos hay elementos encontrados:
Identifiqué que la organización estudiantil no es puramente estudiantil, que hay intereses políticos por otros lados, y que no es simple y llanamente filantrópica, que no simplemente vamos a luchar por la justicia. Hay grupos que necesitan que tú estés movilizado (Estudiante_01).

Para este activista, la acción colectiva tuvo discordancias con respecto a su objetivo inicial y auténtico, con demandas legítimas. De esta manera, al interior hubo juegos políticos de poder en su organización y su representación que respondieron a otros fines. Para este estudiante, la ilusión que tenía sobre la acción colectiva e incluso los movimientos estudiantiles se borró y dio paso a una experiencia distinta: donde también existen grupos de poder que los cooptan. Otros estudiantes señalan:

Se peca de soberbia, es decir creemos que podemos transformar la sociedad en el marco de estas cuatro paredes que llamamos universidad (Estudiante_04).

En los paros que he estado siempre hay vatos [hombres] hay autoritarismo [...] en el paro del tres de septiembre un uruguayo [hombre] agredió a una compañera mientras dormía (Estudiante_07).

Desde la mirada de los activistas la organización de acción colectiva presentó fallas y debilidades. Según los testimonios que expresaron las estudiantes, los líderes del movimiento dieron poca aprobación (con expresiones de corte machista) a que las mujeres se organizaran de manera separada, en una institución donde se reclama la igualdad de género y se llevan a cabo acciones para lograrla. Otra incongruencia, es que prevalecen los estereotipos de que los dirigentes de las acciones y su organización deben ser hombres, mientras que las mujeres son su apoyo, no sus pares.

Un elemento constantemente referido es al acercamiento que debe tener la acción colectiva con otros grupos de la sociedad, es decir, los estudiantes entrevistados afirman que se hacen paros de actividades 
en la Universidad con el fin de cambiar cuestiones del país con lo cual la demanda no trasciende, ya que existe una suerte de ensimismamiento pues no se organizan acciones que interpelen a otros actores sociales. En este sentido, se observa que la lógica de subjetivación es la posición más crítica de los actores ante su experiencia social en la acción colectiva, donde hacen un balance para establecer las debilidades que se presentaron y también los siguientes compromisos que entablarán con la protesta y participación política en la UNAM.

\section{Consideraciones finales}

Con el desarrollo de esta investigación, se identificaron algunos elementos de la acción colectiva de septiembre de 2018 emprendida por la comunidad estudiantil, la cual fue detonada por las agresiones de los porros en la explanada de Rectoría. Las acciones colectivas son consecuencia de malestares y conflictos que viven las comunidades por un periodo considerable y que, súbitamente, se presentan sucesos que pueden desencadenar la protesta. En la UNAM los movimientos estudiantiles y acciones colectivas se han caracterizado por actos de violencia hacía los estudiantes, académicos e incluso autoridades, pero siempre involucrando una lucha de poder político (por ejemplo, los de 1968, 1972, 1999), mientras que la acción colectiva de 2018 se dio en un contexto de robos, asesinatos, tráfico de drogas y violencia de género en los diferentes planteles de la institución y los estudiantes han comenzado a visibilizar estos problemas hacía las autoridades universitarias.

En este estudio se presentó la discusión de cómo clasificar este tipo de manifestaciones: movimiento estudiantil o acción colectiva. Se optó por esta última por la composición y duración de las expresiones estudiantiles. Resalta el hecho de que un grupo pequeño de estudiantes haya tenido la capacidad de convocatoria y movilización de una parte muy significativa de la comunidad universitaria de la UNAM y otras instituciones de educación superior.
Con respecto a la experiencia social de los participantes del estudio, con la acción colectiva de septiembre de 2018, se encontró que para algunos fue su entrada al análisis de situaciones problemáticas que vive la UNAM y al aprendizaje de la protesta estudiantil. Para otros activistas fue otra faceta en su trayectoria como actores altamente politizados en la UNAM. Estos actores se agruparon como una comunidad para la acción colectiva. Y su experiencia social en ésta se distingue por un alto cuestionamiento y crítica permanente a la política del país, la UNAM y la valoración a las mismas acciones que emprendieron. Se observó que la experiencia social de los estudiantes se canalizó hacia un debate sobre la organización y trayectoria que se siguió en la protesta. De acuerdo con Dubet (1994), la experiencia social es crítica porque los actores sociales pasan su tiempo explicando lo que hacen, por qué lo hacen y para qué lo hacen. Una suerte de justificación permanente. Así, la experiencia social de los activistas fue un ejercicio crítico, lo que probablemente será un sedimento para sus siguientes experiencias tanto en acción colectiva como en su ejercicio profesional al egresar de la universidad. Los estudiantes coinciden en que la acción colectiva que se desplegó, en aras de lograr una transformación en la estructura universitaria, quedó limitada, en función de que los activistas agotaron algunos recursos como marchas y paros, $y$ eso les impidió construir mecanismos más efectivos, capaces de trascender al aparato institucional e involucrar a otros actores políticos de la sociedad.

Es notorio que los estudiantes entrevistados en su participación de la acción colectiva vivieron no sólo emociones como el miedo, la ira o la impotencia, sino que la coyuntura también les permitió experimentar la solidaridad entre compañeros universitarios, generar amistades entre activistas y consolidar aprendizajes en torno a las formas de organización estudiantil.

Recuperando lo anterior, esta movilización se puede considerarse como una experiencia inacabada. 
Sin embargo, sí logró posicionar problemáticas a la luz de la comunidad universitaria y deja también una generación de estudiantes con aprendizajes políticos en torno a la lucha estudiantil, atenta al futuro de la universidad y del país.

Un elemento que quedó pendiente en este artículo fue que en la acción colectiva de septiembre de 2018 hubo una organización separada de las mujeres denominada Asamblea Interuniversitaria de Mujeres. Desde hace algunos años en la UNAM hay un reclamo de las estudiantes por demandar respeto, igualdad, seguridad y evidenciar abusos. Las mujeres se destacaron por su alta organización, su capacidad

\section{Referencias}

Aranda, José (2000), "El movimiento estudiantil y la Teoría de los movimientos sociales", Revista de Ciencias Sociales, vol. 7, núm. 21, pp. 224-250.

Berger, Peter y Tomas Luckmann (2001), La construcción social de la realidad, Buenos Aires, Amorrortu.

Camacho, Fernando (2018), "Graue: la UNAM agraviada por la violencia porril”, La fornada, año 34, núm. 12252 (5 de septiembre), Ciudad de México, pp. 33.

Coulon, Alain (2005), Le Métier d'Étudiant. L'entrée dans la vie universitaire, París, Anthropos.

Cruz, Juan Carlos (2018), "Despierta otra vez la UNAM", Proceso, núm. 2184 (9 de septiembre 2018), Ciudad de México, pp. 6-9

Dubet, Françoise (2011), La experiencia sociológica, Barcelona, Gedisa.

Dubet, Françoise (2005), "Los estudiantes", Revista de Investigación Educativa, pp. 1-78, <https://www.uv.mx/ cpue/num1/inves/completos/Dubet.pdf> [Consulta: enero de 2019]

Dubet, Françoise (1994), Sociologie de l'expérience, París, Seuil. de diálogo y la incorporación en el pliego petitorio de la erradicación de la violencia de género, lo que las convierte en un actor político relevante que se necesita analizar. Ahora bien, uno de los retos de esta investigación fue ordenar y sistematizar los sucesos de septiembre de 2018 en la UNAM, dado que hay poca información al respecto. Con los materiales hemerográficos, comunicados de funcionarios, pliegos petitorios se intentó construir una cronología para abonar a la comprensión del conflicto. Sin embargo, reconocemos que es perfectible en la medida del desarrollo de más investigaciones que atiendan a esta problemática.
Durkheim, Emile (1991), Educación y sociología, México, Colofón.

García, Mónica (2011), "Narrativas de movimientos estudiantiles en México: reflexión crítica desde el análisis político del discurso y la perspectiva de género", en Sujetos de la educación, México, XI Congreso Nacional de Investigación Educativa.

Garreton, Manuel (1987), El movimiento estudiantil: conceptos e historia, Santiago, Ediciones Sur.

Garrido, Sebastián (2015), "Masas críticas y redes sociales: una explicación microestructural del surgimiento de cuatro movimientos estudiantiles en la UNAM (19862000)", en Renate Marsiske (coord.), Movimientos estudiantiles en la historia de América Latina, México, Instituto de Investigaciones sobre la Universidad y la Educación, UNAM, pp. 255-307.

Gibss, Graham (2014), El análisis de datos cualitativos en Investigación Cualitativa, Madrid, Morata.

Graue, Enrique (2018a), "Pronunciamiento del Rector de la UNAM", Boletín UNAM-DGCS, núm. 572, 12 de septiembre. 
Graue, Enrique (2018b), "Acude el Rector al CCH Azcapotzalco y acepta nueve puntos delpliego petitorio", Boletín UNAM-DGCS, núm. 541, 4 de septiembre.

Guzmán, Carlota (2012), "Quedar afuera: experiencias y vivencias de los jóvenes que no logran ingresar a la Universidad", Cultura y Representaciones Sociales, año 6, núm. 2, pp. 132-164.

Lomnitz, Larissa (1989), "Los usos del miedo: bandas de porros en México", Cuadernos del CESU (16), México, CESU-UNAM, pp. 49-54

Lozano, Elí (2017), "El camino de la disidencia: cultura y formación política de estudiantes activistas universitarios", Tesis doctoral, México, Facultad de Estudios Superiores Iztacala, Universidad Nacional Autónoma de México.

Mc Adam, Doug et al. (2001), Dynamic of contention, Cambridge, Cambridge University Press.

Marsiske, Renate (2011), "Universidades, clases medias, y movimientos estudiantiles en América Latina (19181929)", tesis doctoral, México, Universidad Nacional Autónoma de México.

Melucci, Alberto (1991), "La acción colectiva como construcción social", Revista de Estudios Sociológicos, vol. IX, núm. 26, pp. 357-364, <https://estudiossociologicos. colmex.mx/index.php/es/article/view/91 1> [Consulta: marzo de 2020].

Mora, Sindy (2008), "Diez años de acción colectiva en Costa Rica", Revista Centroamericana de Ciencias Sociales, vol. V, núm. 1, pp. 131-168, < https://dialnet.unirioja. es/servlet/articulo? codigo $=3045828>$ [Consulta: marzo de 2020].

Ordorika, Imanol (2008), "Violencia y porrismo en la educación superior en México", en Teresinha Bertussi (coord.), Anuario educativo mexicano: una visión retrospectiva, año 2005, México, UPN/Miguel Ángel, Porrúa, pp. 459-475.
Palomino, Laura (2010) "El sentido de la acción colectiva en el movimiento estudiantil 1999-2000", Revista Electrónica de Psicología en Iztacala, vol. 13, núm. 2, <http://www.revistas.unam.mx/index.php/repi/ article/view/17661> [Consulta: enero de 2019].

Sánchez, Arturo (2018), "Más participación en toma de decisiones, salida a la violencia de la UNAM: Graue", La fornada, año 34, núm. 12287 (11 de octubre), p. 18.

Sánchez, Arturo y Fernando Camacho (2018a), "Acabar con el porrismo en las universidades, exigen miles en CU”, La fornada, año 34, núm. 12253 (6 de septiembre), p. 3.

Sánchez, Arturo y Fernando Camacho (2018b), "El rechazo a la violencia y a los porros convocó a miles en CU”, La fornada, año 34, núm. 12255 (8 de septiembre), p. 5.

Sánchez, Arturo y Fernando Camacho (2018c), "Erradicar a grupos porriles de centros educativos, exigen miles", La fornada, año 34, núm. 12261 (14 de septiembre), p. 3. Sánchez, Arturo y Fernando Camacho (2018d), "Esperan que hoy haya acuerdos en la asamblea interuniversitaria", La fornada, año 34, núm. 12262 (15 de septiembre), p. 5

Tarrow, Sidney (1997), El poder en movimiento. Los movimientos sociales, la acción colectiva y la política, Madrid, Alianza Editorial.

Tricot, Tokichen (2012), "Movimiento de estudiantes en Chile: repertorios de acción colectiva calgo nuevo?", Revistaf@ro, vol. 1, núm. 15, pp. 1-12, <https://www. revistafaro.cl/index.php/Faro/article/view/63/0> [Consulta: marzo de 2020].

Touraine, Alain (1987), El regreso del actor, Buenos Aires, Editorial Universitaria de Buenos Aires.

Vasilachis, Irene (2006), "La investigación cualitativa", en Irene Vasilachis (coord.), Estrategias de investigación cualitativa, México, Gedisa, pp. 23-64. 
Anexo 1. Cronología de la acción colectiva de septiembre y octubre de 2018

\begin{tabular}{|c|c|c|}
\hline Fecha & Suceso & Actores involucrados \\
\hline 27 de agosto & Paro estudiantil cCH-Azcapotzalco & Estudiantes CCH-Azcapotzalco \\
\hline 27 de agosto & Agresión de porros a la comunidad estudiantil CCH-Azcapotzalco & Grupos de porros \\
\hline 28 de agosto & $\begin{array}{l}\text { Presentación de pliego petitorio por parte de los estudiantes del CCH- } \\
\text { Azcapotzalco a las autoridades }\end{array}$ & Estudiantes $\mathrm{CCH}$-Azcapotzalco \\
\hline 03 de septiembre & Marcha estudiantil del cCH -Azcapotzalco al edificio de Rectoría & Estudiantes de CCH -Azcapotzalco ENP y FFyL \\
\hline 03 de septiembre & $\begin{array}{l}\text { Agresión de porros a los estudiantes que se manifestaban en la explanada de } \\
\text { Rectoría }\end{array}$ & $\begin{array}{l}\text { Grupos porriles: "Treinta y dos", "Tres de Marzo" } \\
\text { y "Federación de Estudiante de Naucalpan" }\end{array}$ \\
\hline 03 y 04 de septiembre & Establecimiento de paros en 40 planteles de la UNAM & Asambleas estudiantiles de cada entidad \\
\hline 04 de septiembre & $\begin{array}{l}\text { Rectoría condena los actos violentos y hace un ofrecimiento de diálogo con } \\
\text { las comunidades afectadas. }\end{array}$ & Enrique Graue \\
\hline 05 de septiembre & Marcha estudiantil en el campus de Ciudad Universitaria & Estudiantes de la UNAM y otras IES \\
\hline 05 de septiembre & $\begin{array}{l}\text { Anuncio de la expulsión de la UNAM de } 18 \text { porros que participaron en las } \\
\text { agresiones }\end{array}$ & Enrique Graue \\
\hline 06 de septiembre & Rectoría suspende a Teófilo Licona, coordinador de auxilio UNAM & Enrique Graue \\
\hline 07 de septiembre & $\begin{array}{l}\text { Asamblea Interuniversitaria para presentar pliegos petitorios de cada } \\
\text { comunidad }\end{array}$ & $\begin{array}{l}\text { Representantes estudiantiles de las diferentes } \\
\text { entidades de la UNAM y de otras IES }\end{array}$ \\
\hline 10 y 11 de septiembre & Levantamiento de paros en gran parte de las ENP, CCH y facultades & Asambleas estudiantiles de cada entidad \\
\hline 12 de septiembre & $\begin{array}{l}\text { Reunión de Rectoría con la comunidad estudiantil del CCH-Azcapozalco para } \\
\text { dar respuesta a las demandas }\end{array}$ & $\begin{array}{l}\text { Asamblea estudiantil del CCH-Azcapozalco y } \\
\text { Enrique Graue }\end{array}$ \\
\hline 13 de septiembre & $\begin{array}{l}\text { Marcha del silencio del Ángel de la Independencia al Zócalo de la Ciudad de } \\
\text { México }\end{array}$ & Estudiantes de la UNAM y de otras IES \\
\hline 14 de septiembre & Asamblea Interuniversitaria para acordar pliego petitorio & $\begin{array}{l}\text { Representantes estudiantiles de las diferentes } \\
\text { entidades de la UNAM y de otras IES }\end{array}$ \\
\hline 24 de septiembre & Levantamiento de paro en la FFyL & Asamblea de estudiantes de la FFyL \\
\hline 29 de septiembre & Asamblea Interuniversitaria para acordar pliego petitorio & $\begin{array}{l}\text { Representantes estudiantiles de las diferentes } \\
\text { entidades de la UNAM y de otras IES }\end{array}$ \\
\hline 10 de octubre & Presentación de pliego petitorio a las autoridades de la UNAM & Representantes de la Asamblea InterUNAM \\
\hline 12 de octubre & Presentación de pliego petitorio al Congreso de la Unión & Representantes de la Asamblea Interuniversitaria \\
\hline
\end{tabular}

\section{Cómo citar este artículo:}

Cuevas, Yazmín, Melisa-Yolanda Pasos-Osnaya y Erika Romo-Romo, (2021), "Estudiantes activistas de la Facultad de Filosofía y Letras y su experiencia social en la acción colectiva de septiembre de 2018”, Revista Iberoamericana de Educación Superior (RIES), vol. XII, núm. 34, pp. 176-195, DOI: https://doi.org/10.22201/iisue.20072872e.2021.34.986 [Consulta: fecha de última consulta]. 